\title{
ANALISIS RANGKAIAN SOSIAL TERHADAP PEMAIN UTAMA DALAM MEMPERKASAKAN KEMPEN BEBAS BEG PLASTIK DI KUANTAN PAHANG
}

\author{
MUHAMMAD AFIQ 'AIZUDDIN MD DIN DAN LATIFAH ABDUL GHANI”
}

Faculty of Business, Economic and Social Development, Universiti Malaysia Terengganu, Terengganu, Malaysia

*Corresponding author: latifah.ghani@umt.edu.my

http://doi.org/10.46754/umtjur.2021.01.012

\begin{abstract}
Abstrak: Penggunaan beg plastik sangat popular di seluruh dunia. Di Malaysia beg plastik menjadi keperluan masyarakat terutama dalam proses jual beli. Peningkatan itu sekaligus mewujudkan kebimbangan bagi pemain utama seperti kerajaan persekutuan yang berperanan menggerak dan memperjuangkan kelestarian alam sekitar. Kempen bebas beg plastik merupakan kempen yang kerap dilaungkan dalam menggubah budaya penggunaan plastik dalam kehidupan seharian. Menerusi pelaksanaan kempen bebas beg plastik yang dijalankan di seluruh negeri khususnya di Kuantan, Pahang, maka kajian ini dapat mengkaji rangkaian pemain utama dengan menggunakan kaedah kualitatif temubual melalui Analisis Rangkaian Sosial (ARS). Secara khususnya, rangkaian tadbir berjaya memaparkan pelbagai saliran berkaitan komunikasi dan kerjasama antara pemain utama. Struktur berpusat didapati menjadi asbab kepada kapasiti terhad dalam menyelaraskan tindakan bersama. Temubual yang mendalam menunjukkan kepentingan kedudukan pemain utama dalam rangkaian tindakan bersama memudahkan pihak terlibat. Hasil kajian menunjukkan peluang lebih berkesan dan realistik jika diselaras hukuman dan tindakan di peringkat persekutuan dengan kerjasama Majlis Perbandaran, Jabatan Alam Sekitar, institusi penyelidikan, organisasi perniagaan dan pemain lain yang berkaitan. Justeru, kajian akan datang harus memperkasakan pendidikan dalam kalangan masyarakat dari setiap lapisan umur, kaum dan agama serta budaya. Malah, penerokaan terhadap keberkesanan penyampaian dan penerangan maklumat perlu divisualkan secara jelas oleh pihak berkepentingan dalam usaha mensifarkan penggunaan beg plastik di Malaysia.
\end{abstract}

Kata Kunci: Beg plastik, rangkaian tadbir, kempen, pemain utama, Analisis Rangkaian Sosial (ARS)

\section{SOCIALNETWORKINGANALYSISOFMAJOR PLAYERS IN STRENGTHENING FREE PLASTIC BAG CAMPAIGN IN KUANTAN, PAHANG}

\begin{abstract}
The use of plastic bags is very popular around the world. In Malaysia, plastic bags are necessity for the people especially in process of buying and selling. The increase is an ongoing concern for major players such as the federal government who fought for environmental sustainability. The plastic bag-free campaign is a campaign that the players often use to propagate the changing culture of plastic use in life. Through the implementation of free plastic bags campaign conducted throughout the country, especially in Kuantan, Pahang, this study was able to study the mainstream network using the qualitative method of interviews through Social Network Analysis (SNA). In particular, this governance network presents a wide range of channels that are interconnected with strong communication and collaboration between key players. The centralized structure causes limited capacity in harmonizing common actions. In-depth interviews show the importance of key players in the network to facilitate and coordinate joint action between key players. The findings show a more effective and realistic opportunity if coordinated federal action and punishment in which the motion was tabled at the Parliament by the relevant minister
\end{abstract}


for debate and obtained two-thirds of parliamentarians' approval to enforce the ban on the use of plastic bags and cooperate with the municipalities, environmental departments, research institutions, business organizations and other relevant players. Hence, future studies have to empower education in the community from every age, race and religion and culture. In fact, the exploration of the effectiveness of information delivery needs to be clearly visualized in every explanation by key stakeholders in the effort to pursue the use of plastic bags in Malaysia.

Keywords: Plastic bags, governance networks, campaigns, major players, Social Network Analysis (SNA).

\section{Pengenalan}

Penyediaan beg plastik dalam proses jual beli di antara penjual dan pembeli atau pengguna menjadi amalan biasa dan di anggap penting sebagai hak pengguna (Tan \& Mehta, 1994). Penggunan beg plastik percuma dianggap penyediaan rutin yang tidak memberi kesan kepada alam sekitar sekaligus tidak mempunyai nilai ekonomi tersendiri (Akulian et al., 2007). Oleh itu, cabaran memperkenalkan bayaran beg plastik ketika membeli-belah di hujung minggu menjadi permulaan tindakan pendidikan buat pengguna.

Kementerian Perdagangan Dalam Negeri, Koperasi dan Kepenggunaan (KPDNKK) telah melancarkan Hari Kempen Bebas Beg Plastik pada bulan Januari 2011, bagi mengurangkan penggunaan beg plastik berlebihan di samping dapat menyelamatkan alam sekitar (KPDNKK, 2012). Dasar baharu yang digerak pemain utama itu, turut mengenakan caj beg plastik yang mulanya tidak menjadi amalan mesra pengguna. Kempen itu berlangsung setiap hari Sabtu di super atau hypermarket terpilih, pusat peruncitan utama dan pusat membeli-beli di seluruh negara. Caj dikenakan bernilai RM 0.20 (USD 0.6) ditolak sekaligus mencetuskan kebencian di kalangan pengguna bagi tempoh tiga hingga enam bulan pertama sepanjang kempen berjalan (The Star, 4 Januari, 2010).

Pemain industri seperti sektor peruncit, barangan peruncit dan industri plastik membantah objektif caj cukai alam sekitar yang menfokuskan penggurangan dan limitasi pencemaran luaran kepada alam sekitar (Pigou, 1920). Pelaksanaan cukai caj itu tidak dapat merangsang perubahan tingkah laku penggguna, meminimumkan sampah atau penggunaan berlebihan daripada bahan plastik (Park, 2009). Namun, pengguna masih mempunyai pilihan menggelak kadar caj itu dengan membawa beg runcit sendiri. Dalam kes ini, cukai caj mungkin tidak berfungsi sebagai Cukai Pigouvian di mana faedah marginal pengantarabangsaan adalah sama dengan penggurangan kos marginal, tetapi adalah untuk memberi isyarat harga sehingga tahap yang mampu merangsang kepada perubahan tingkah laku pengguna. Dalam kebanyakan negara seperti Denmark, United Kingdom, Ireland dan Afrika Selatan, kerajaan menjadi pemain utama dalam mengamalkan cukai caj beg plastik dengan mempengaruhi penyertaan pengguna dalam penggunaan yang mampan hingga menggalakkan kepada tingkahlaku proaktif pengguna terhadap alam sekitar (Convery \& Hasson, 2007). Aspek ini penting untuk menilai tahap penerimaan pengguna dari sudut kesedaran, pengetahuan dan sikap mereka, sekaligus sokongan itu dapat menyediakan maklumat penting buat pemain-pemain utama untuk terus menggerakkan peranan masing-masing (Sharp, 2010; Baker, 2010).

Namun, langkah pemerkasaan yang diambil dalam menggerak dasar kelestarian itu dilihat masih mengalami tempoh sukar. Pemerkasaan merupakan satu proses perubahan dalaman yang bertujuan meningkatkan keupayaan 
atau keberkesanan dari sesuatu program yang dibuat (Mayoux, 1998). Walaupun terdapat beberapa pemain mengambil inisiatif dengan memberikan bantuan atau pendidikan awal dengan menyediakan beg kertas serta menyatakan kempen "Katakan Tidak Kepada Beg Plastik", namun ia tidak menjamin kelangsungan kesedaran pengguna pada masa akan datang. Hal ini kerana, pembangunan sosial tidak boleh berlaku tanpa pembangunan ekonomi manakala pembangunan ekonomi pula tidak akan memberi makna jika perkara tersebut tidak dapat membuat perubahan signifikan terhadap kesejahteraan sesebuah masyarakat (Midgley, 1995).

Oleh itu, pemain utama iaitu pihak kerajaan persekutuan perlu melaksanakan langkah drastik melalui perlaksanaan akta bersifat kekal untuk mewujudkan sikap berdikari dalam masyarakat yang secara tidak langsung meningkatkan pemikiran mereka melalui pendidikan dan penetapan undang-undang. Masyarakat sebagai pengguna perlu melibatkan diri secara keseluruhan sekaligus mengubah mentaliti mereka dalam usaha mempertingkatkan kualiti kehidupan sejagat. Penglibatan komuniti itu merupakan satu bentuk tindakan sukarela melalui individu yang ingin mengambil peluang dan memikul tanggungjawab kemasyarakatan (Tosun, 2000).

Sebagai medium atau perantaraan, pendayaupayaan, tahap penyertaan serta penglibatan memainkan peranan penting bagi menentukan kejayaan sesuatu dasar dan program yang ingin dilaksanakan. Maka, keterlibatan pengguna dalam pembuatan keputusan dan perlaksanaan program merupakan pendekatan bawah-atas yang efektif dalam menangani masalah terutama perihal pencemaran alam sekitar di kawasan setempat. Namun begitu, kebanyakkan program atau dasar yang dilaksanakan di Malaysia adalah bersifat atas-bawah yang tidak meletakkan perspektif pengguna sebagai asasnya. Hanya melalui penglibatan dalam perlaksanaan program, pengguna tidak dapat menyuarakan keperluan mereka, yang jelas mengehadkan perubahan yang diinginkan sekaligus matlamat utama Kempen Bebas Beg Plastik sukar dicapai.

Walaubagaimanapun, setiap pembangunan sesuatu dasar mempunyai tahap ukuran bagi menilai keberkesanan terhadap program atau aktiviti yang dilakukan. Pemain utama meletakkan permasalahan kajian sebagai pengukur dalam menentukan tahap pembangunan kelestarian alam sekitar. Di Malaysia, indikator pengumpulan sampah sarap plastik secara harian dinilai sebagai tahap pembangunan kelestarian alam sekitar. Pemerkasaan dasar tersebut merupakan aspek yang diberi penekanan oleh agensi kerajaan dan turut menjadi fokus oleh organisasi antarabangsa. Oleh itu, pemain utama seperti Jabatan Alam Sekitar, Majlis Perbandaran, Alam Flora serta agensi SWCorp kriteria yang diambilkira bagi menentukan tahap kelestarian alam sekitar.

Secara keseluruhannya, indikator menfokuskan tiga perkara dalam menjamin tahap penjagaan dan pengurusan alam sekitar oleh sesebuah masyarakat seperti yang dinyatakan oleh Midgley (2005), iaitu pengurusan masalah pencemaran disebabkan oleh masyarakat yang tidak mempunyai kesedaran tinggi dalam penjagaan alam sekitar dari peringkat lebih awal. Berpandukan perkara pertama yang disebut, pemain-pemain utama ini mampu mengenalpasti tahap pembangunan kelestarian alam sekitar melalui pengurusan sisa buangan beg plastik, di mana jelas masalah utama bahan tersebut ialah mengambil masa lama untuk reput dan terurai berikutan ianya mempunyai bahan kimia yang mampu merosakkan nutrisi tanah.

Seterusnya, pemain utama melalui kementerian yang berkaitan dapat mengukur tahap penerimaan rakyar berpandukan 
keberkesanan dasar bebas beg plastik yang dilaksanakan dengan kerjasama pelbagai agensi. Akhir sekali, badan bukan kerajaan (NGO) juga dapat membantu menyediakan kesejahteraan sosial melalui penyediaan beg kertas di lokasi pasaraya sekaligus dapat meningkatkan potensi pengguna untuk menerima dasar berkenaan.

Dengan permasalahan kajian yang dihuraikan, Mold an Dieu (2006) berhasil mengenalpasti beberapa jenis analisis yang tidak memberi ruang kepada lontaran pandangan, pemahaman dan strategi mengenai bagaimana sesebuah tadbir urus negara mampu menguruskan aliranaliran sumber ke arah pembangunan yang mampan. Pihak tersebut hanya memberi sedikit perhatian kepada sistem dan rangkaian sosial seperti interaksi sosial dan dinamik, serta hubungan kuasa yang memerintah untuk kelestarian alam sekitar (Ibid, 2004). Oleh itu, sumbangan sosiologi dalam analisis aliran larangan beg plastik yang mencakupi aspek diatas, merupakan pelengkap yang perlu diteliti dalam memperkasa kempen berkenaan.

Maka, matlamat kajian ini adalah untuk mengkaji aspek sosial dan tadbir urus dengan menganalisis rangkaian pemain utama iaitu pihak berkepentingan bagi memperkasakan kempen bebas beg plastik agar ia dipatuhi semua lapisan masyarakat di Malaysia. Konsep rangkaian tadbir urus akan digunakan dalam kajian ini sebagai rangka kerja konseptual, di mana berteraskan konsep "top-down" iaitu sistem berpusat dari atas ke bawah yang meletakkan kerajaan sebagai pemain utama dalam pembuatan sesuatu keputusan, dasar atau akta yang dilihat kurang sesuai untuk menjadi pengurusan utama terhadap sumber-sumber semula jadi (Carlsson \& Sandstroem, 2007).

Penyelidikan mendalam terhadap bidang rangkaian sosial dan tadbir urus sumber asli menunjukkan bukan sahaja kewujudan rangkaian sosial menjadi kejayaan proses tadbir urus sumber asli, malah ia juga melibatkan penyertaan semua struktur rangkaian terpenting (Bodin \& Crona, 2009; Bodin \& Prell, 2011; Carlsson \& Sandstroem, 2007). Struktur di atas merujuk kepada corak interaksi di kalangan ahli-ahli rangkaian sosial iaitu bagaimana cara mereka saling berhubung dan berkomunikasi antara satu sama lain dalam mencapai kesepakatan perlaksanaan sesuatu program atau dasar yang dibuat.

Dalam kajian ini, kaedah "Analisis Rangkaian Sosial” (ARS) telah digunakan untuk menganalisis struktur rangkaian sosial ini secara kualitatif dan sistematik. ARS akan menyiasat struktur komunikasi dan interaksi ahli melalui maklumat, pengetahuan dan sumber tunai. Penggunaan kaedah ini, jelas membolehkan pengkaji mendedahkan struktur rangkaian yang boleh mengekang proses komunikasi dan kerjasama antara pihak berkepentingan ke arah memperkasakan kempen bebas beg plastik.

\section{Kaedah Kajian}

Teknik kualitatif telah digunakan dalam kajian ini dengan mengumpul dan menganalisis data primer dan sekunder. Matlamat kaedah ini agar kajian yang dijalankan akan lebih sempurna dan tersusun serta selaras dengan objektif kajian. Kaedah temubual dan wawancara mendalam telah digunakan dan data direkodkan dalam pangkalan inventori data. Kaedah ini digunakan untuk memudahkan mengumpul dan mendapatkan data rangkaian sosial yang setara dengan cara seragam yang mana diperlukan untuk melengkapkan kajian ini. Pendekatan penyelidikan secara kualitatif telah digunakan dalam kajian ini supaya perspektif penting dapat dilibatkan bersama dan dapat mempertimbangkan perspektif subjektif pelakon yang terlibat jua (Flick, 2006).

Kaedah kualitatif digunakan dalam kajian ini sebagai hasil kajian 
kerana penggunaan kaedah ini boleh digeneralisasikan dari sampel kepada populasi. Kaedah yang digunakan dalam kajian ini adalah berbentuk empirikal. Pengkaji akan pergi ke lapangan bagi mengumpul data daripada informan dan responden di Kuantan, Pahang.

Instrumen yang digunakan adalah dengan menemubual informan dan mengumpulkan maklumat daripada responden menggunakan wawancara mendalam. Temu bual mendalam adalah satu teknik penyelidikan kualitatif yang melibatkan menjalankan temu bual individu intensif dengan sebilangan kecil daripada responden untuk meneroka perspektif mereka pada idea, program, atau keadaan(Boyce \& Neale, 2006). Walaupun ianya adalah salah satu kaedah penyelidikan kualitatif yang paling biasa (Mack et al., 2005; Mayring, 2002), terdapat beberapa kekangan dan kesulitan yang berkaitan dengan temu bual seperti kesuntukan masa dan kekurangan pemain yang berkaitan kerana kepentingan responden dalam pemerkasaan kempen ini yang dikaji dan bukan 'generalizability' keputusan kerana sampel bersaiz kecil. Kaedah penyelidikan ini juga membolehkan proses 'discovery oriented' terbuka dan membolehkan penyelesaian sesuatu isu dan perspektif. Secara langsung, wawancara mendapatkan sekurang-kurangya perspektif interpretif iaitu maklumat kenalan, hubungan dan percanggahan idea dan pendapat berkenaan peristiwa tertentu, fenomena dan perkembangan (Mack et al., 2005). Hal ini membolehkan para penyelidik mengumpul maklumat latar belakang dan pandangan dalam tempoh masa yang singkat serta sangat berguna apabila subjek ini dikaji secara kompleks dengan jelas (Cordell, 2010; Guion, Diehl \& McDonald, 2011; Lommen, 2010).

Nama-nama untuk kajian rangkaian sebahagiannya telah dikumpul semasa temu bual dengan pihak berkepentingan. Dalam pengertian ini, temubual merupakan bahagian yang wujud dalam proses pensampelan bola salji dan digunakan untuk menghasilkan nama-nama baru untuk ARS. Data kualitatif ini juga bertujuan untuk melengkapkan data kaji selidik itu yang hanya menyediakan gambar rangkaian pihak berkepentingan pada masa tinjauan. Oleh itu, ia tidak mempunyai satu dimensi dinamik kerana ia tidak memberikan apa-apa maklumat keupayaan rangkaian untuk memupuk sifat kesedaran bahawa penggunaan beg plastik mampu menjejaskan alam sekitar di masa akan datang.

\section{Keputusan dan Perbincangan}

\section{Rangkaian Pihak Berkepentingan}

Analisis rangkaian terdiri daripada 38 orang yang mewakili 15 organisasi dari pelbagai sektor (atau kategori pelakon) seperti kerajaan persekutuan, kerajaan negeri, institusi penyelidikan, badan bukan kerajaan, pekerja pengurusan sisa sampah, dan sektor komunikasi. Senarai lengkap semua organisasi pihak berkepentingan dan pihak-pihak berkaitan boleh dilihat dalam Jadual 1.

Jadual 1: Senarai Organisasi Sebagai Responden

\begin{tabular}{llccc}
\hline \multicolumn{1}{c}{$\begin{array}{c}\text { Sektor (Kategori } \\
\text { Pemain) }\end{array}$} & \multicolumn{1}{c}{ Organisasi } & Label & $\begin{array}{c}\text { Bilangan } \\
\text { Pemain }\end{array}$ & Komuniti \\
\hline $\begin{array}{l}\text { Kerajaan } \\
\text { Persekutuan }\end{array}$ & $\begin{array}{l}\text { Kementerian Perdagangan } \\
\text { Dalam Negeri dan Hal Ehwal } \\
\text { Pengguna }\end{array}$ & $\begin{array}{c}\text { KPDN- } \\
\text { HEP }\end{array}$ & 1 & Tindakan \\
& Jabatan Alam Sekitar & JAS & 2 & Tindakan \\
\hline
\end{tabular}




\begin{tabular}{llccc}
\hline \multirow{2}{*}{$\begin{array}{l}\text { Kerajaan } \\
\text { Tempatan }\end{array}$} & Majlis Perbandaran Kuantan & MPK & 3 & Tindakan \\
\cline { 2 - 5 } Pengumpulan Sisa & Exco Kerajaan Negeri & EXCO & 2 & Tindakan \\
& $\begin{array}{l}\text { Perbadanan Pengurusan Sisa } \\
\text { Pepejal Dan Pembersihan Awam }\end{array}$ & SWCORP & 3 & Tindakan \\
\cline { 2 - 5 } & Alam Flora & AF & 3 & Tindakan \\
\hline $\begin{array}{l}\text { Institusi } \\
\text { Penyelidikan }\end{array}$ & Universiti Malaysia Pahang & UMP & 2 & Pengetahuan \\
\cline { 2 - 5 } & $\begin{array}{l}\text { Universiti Islam Antarabangsa } \\
\text { Malaysia }\end{array}$ & UIAM & 2 & Pengetahuan \\
\hline Penyiaran & Radio Televisyen Malaysia & RTM & 1 & Tindakan \\
\cline { 2 - 5 } & Sinar Harian & SH & 1 & Tindakan \\
\cline { 2 - 5 } & Berita Harian & BH & 1 & Tindakan \\
\hline $\begin{array}{l}\text { Badan Bukan } \\
\text { Kerajaan (NGO) }\end{array}$ & Persatuan Solidariti Hijau & PSH & 3 & Tindakan \\
\cline { 2 - 5 } & Kuantan Environment Lover & KELC & 2 & Tindakan \\
\hline Pengguna & Club & & & PG \\
\hline JUMLAH & Pengusaha Perniagaan & 5 & Tindakan \\
\cline { 2 - 5 } & Masyarakat Tempatan & & 7 & Pengetahuan \\
\hline
\end{tabular}

\section{Struktur Sosial - Rangkaian Jaringan Sosial Secara Keseluruhan}

Rajah 1 menunjukkan struktur rangkaian secarakeseluruhan yangtelahanalisisdengan mengira ketumpatan nod. Ketumpatan rangkaian adalah ukuran normal pada SNA dan bagaimana dihubungkan rangkaian pemain (Wasserman \& Faust, 1994). Jika hubungan antara ahli-ahli rangkaian diukur menggunakan data binari (0 untuk tiada medium dan 1 untuk sedia ada). Ketumpatan dapat dinyatakan sebagai jumlah hubungan yang sedia ada dalam rangkaian yang dapat berhubung dengan jumlah hubungan yang kemungkinan. Hubungan kerjasama ini akan lebih kuat dengan nilai kewajarannya yang tinggi daripada hubungan yang lemah. Dalam rangkaian ini, sebanyak 38 individu telah berkongsi hubungan sebanyak 670 dengan kemungkinan hubungan sebanyak 1,406. Ini bermakna sebanyak 47.7 peratus daripada semua hubungan mungkin hadir dengan ketumpatan sebanyak 0.477 .

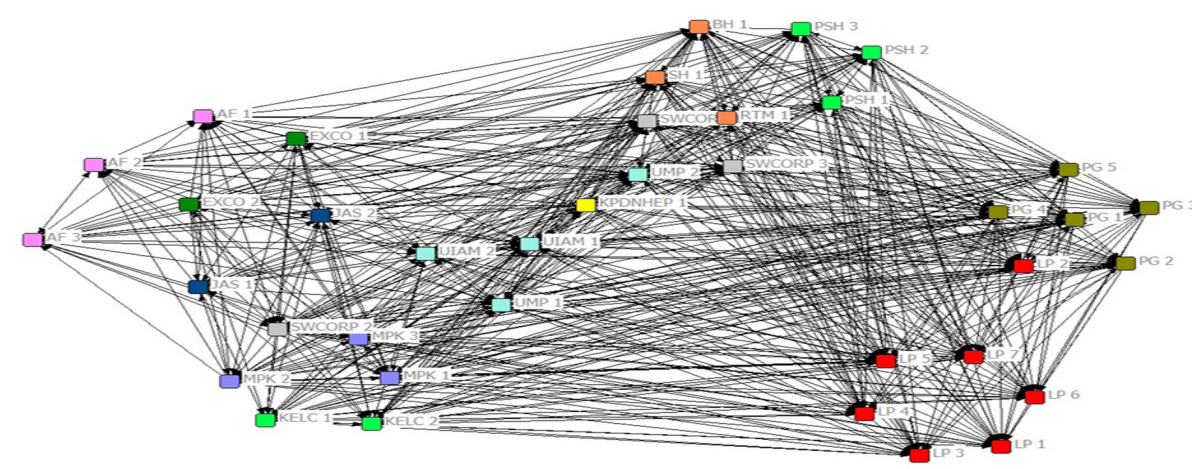

Rajah 1: Peta rangkaian yang mengandungi semua pihak yang berkepentingan $(\mathrm{n}=38)$ dan mempunyai tiga hubungan kekuatan $(1$ = sporadik iaitu pertukaran maklumat, 2 = hubungan tidak rasmi, 3 = kerjasama). Saiz nod menunjukkan keutamaan dalam perantaraan pemain, warna menunjukkan gabungan organisasi. Anak panah menentukan arah tali leher, iaitu sama ada aliran maklumat / kerjasama agak sehala atau dua arah 
Rangkaian dengan pemusatan darjah adalah bernilai 25.91 (Darjah Luar: 27.26, Darjah Dalam: 24.56). Ketumpatan ini menunjukkan bahawa terdapat pihakpihak berkepentingan dalam rangkaian, yang mempunyai lebih banyak hubungan daripada yang lain. Ini digambarkan dengan garisan curam dalam Rajah 2. Dengan kata lain, jumlah hubungan setiap ahli rangkaian adalah tidak sekata ke atas semua ahli rangkaian (dalam kes pengagihan sama garis yang mendatar bagi paksi-x).

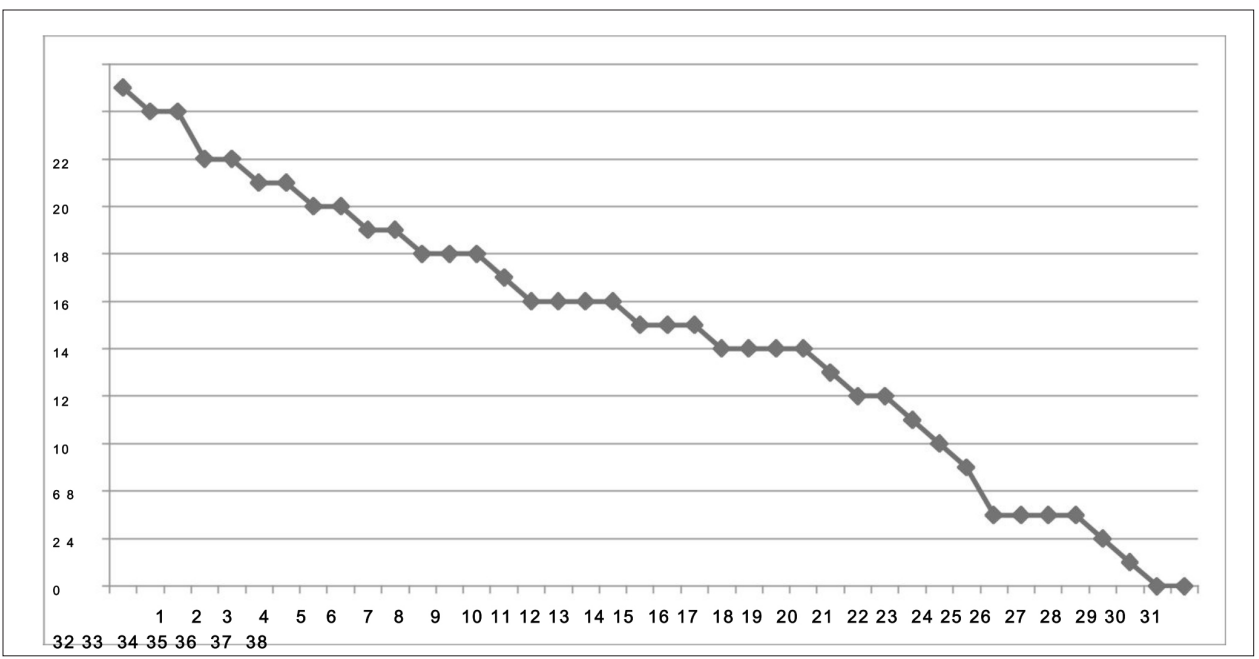

Rajah 2: Rangkaian tahap pemusatan terhadap Pihak Berkuasa Tempatan (MPK). Pemegang kepentingan individu ditunjukkan pada paksi-x, bilangan pautan setiap pihak berkepentingan pada paksi-y

Nilai pemusatan pula adalah rendah dan menunjukkan terdapat rangkaian yang tidak mempunyai teras-pinggir-struktur biasa, di mana beberapa ahli rangkaian mempunyai nilai yang luar biasa tinggi kepusatan hubungan dan menjadi teras rangkaian. Manakala rangkaian (pinggir) yang lain hanya mempunyai beberapa hubungan. Ujian pusat-pinggir untuk ujian P rangkaian mendedahkan bahawa teras terdiri oleh majoriti ahli-ahli rangkaian $(\mathrm{n}=12)$ yang mempunyai ketumpatan hubungan yang tinggi di antara mereka. Manakala, individu lain mempunyai kepadatan hubungan yang sangat rendah di antara mereka kerana kebanyakkan daripada mereka berhubung dengan teras (Rajah 3). 


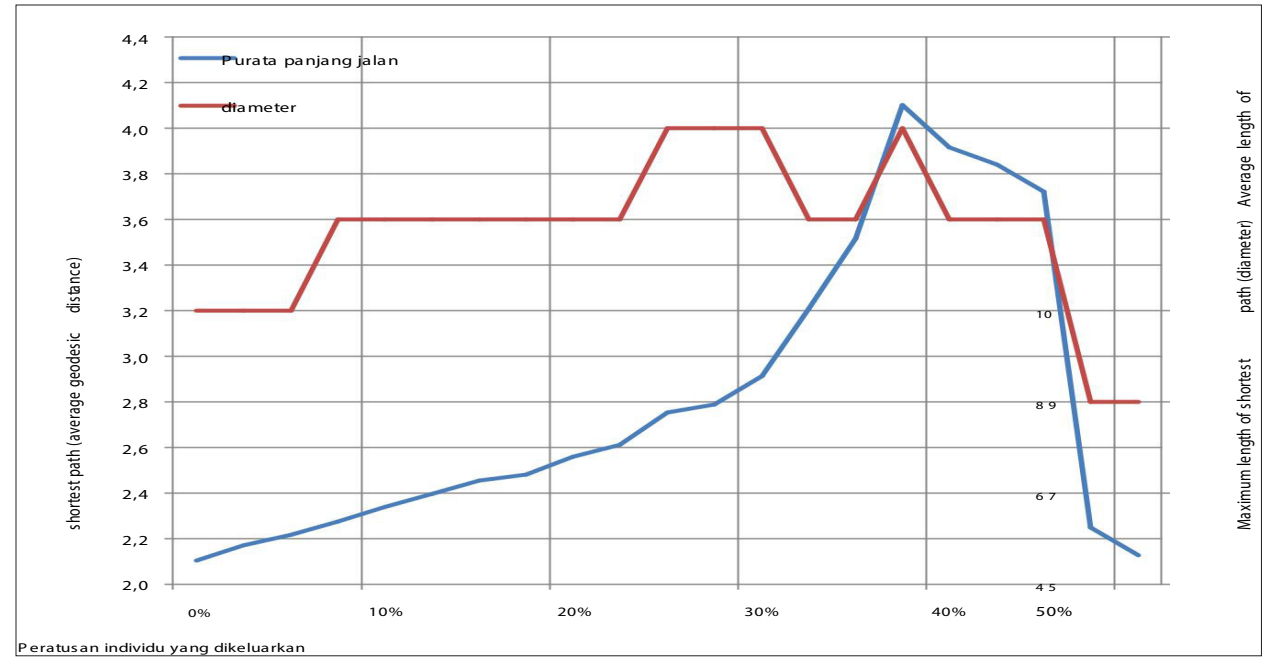

Rajah 3: Perubahan dalam purata jarak dan diameter geodesik sebagai penunjuk daya tahan rangkaian kepada penghapusan individu utama. Penurunan dalam purata jarak dan diameter geodesik seperti $38 \%$ bagi penyingkiran nod telah berlaku apabila nod pada akhir nodus dikeluarkan (rujuk Heinrup, 2012)

\section{Pengaruh Dilihat Melalui Kepakaran}

Jadual 2: Tujuh ahli rangkaian dengan nilai-nilai tertinggi dari segi pengaruh dan kepakaran dilihat mengenai pemerkasaan kempen bebas beg plastik di Kuantan, Pahang.

\begin{tabular}{|llllll|}
\hline \multicolumn{4}{|l}{ Dilihat pengaruh INFL } & \multicolumn{5}{l|}{ Dilihat ertise exp } \\
pihak \\
berkepentingan & Sector & Factor & $\begin{array}{l}\text { pihak } \\
\text { berkepentingan }\end{array}$ & sektor & Factor \\
UMP 1 & Institut Penyelidikan & 3.31 & KPDNHEP & Kerajaan Persekutuan & 3.92 \\
UIAM 2 & Institut Penyelidikan & 3.13 & UIAM 1 & Institut Penyelidikan & 3.86 \\
IAS 1 & Kerajaan Persekutuan & 3.07 & MPK 1 & Kerajaan Negeri & 3.73 \\
AF 1 & Pengumpulan Sisa & 3.07 & MPK 2 & Kerajaan Negeri & 3.58 \\
PSH 1 & Badan Bukan Kerajaan (NGO) & 3.00 & EXCO 1 & Kerajaan Negeri & 3.56 \\
KELC 2 & Badan Bukan Kerajaan (NGO) & 2.88 & EXCO 2 & Kerajaan Negeri & 3.55 \\
PG 1 & Pengguna & 2.80 & SWCorp 1 & Pengumpulan Sisa & 3.53 \\
PG 2 & Pengguna & 2.77 & SWCorp 2 & Pengumpulan Sisa & 3.53 \\
LP 2 & Pengguna & 2.75 & SH & Penyiaran & 3.50 \\
LP 1 & Pengguna & 2.73 & RTM & Penyiaran & 3.50 \\
\hline
\end{tabular}

Jadual 2 menunjukkan tujuh individu yang mempunyai skor tertinggi dari segi pengaruh dalam memperkasakan kempen bebas beg plastik di Kuantan. Seperti yang boleh dijangkakan, dapatan kajian mendedahkan bahawa kebanyakan individu yang mempunyai pengaruh yang tinggi berada pada tahap sektor kerajaan persekutuan atas tindakan itu. Daripada kajian ini, empat daripada tujuh ahli rangkaian di atas sangat pengaruh tertinggi dapat dilihat daripada 
sebahagian sub-kumpulan dua iaitu di tengah-tengah rangkaian pemusatan iaitu kerajaan persekutuan, kerajaan negeri, NGO dan sektor pengumpulan sisa. Kedudukan kedua tertinggi adalah daripada institut penyelidikan di mana peranannya mengkaji sejauh mana keberkesanan dan keterlaksanaan kempen ini mengikut objektif dan matlamat yang ditetapkan. Kedudukan terakhir adalah sektor pengguna yang mana diwakili oleh masyarakat tempatan. Pemain di sektor ini hanya menerima dan akur dengan apa yang telah ditetapkan oleh Majlis Perbandaran
Kuantan kerana kerajaan berhak melakukan apa sahaja demi kepentingan bersama.

\section{Tahap Kesedaran Terhadap Kempen Bebas Beg Plastik}

Kajian ini juga mengukur korelasi sikapsikap untuk menyokong kempen bebas beg plastik menggunakan kod semasa sesi wawancara yang mendalam kepada sokongan ke arah pasaraya dan kekerapan pengguna membawa beg runcit mereka sendiri semasa kempen dalam sebulan.

Jadual 3: Sumber maklumat tentang kempen bebas beg plastik

\begin{tabular}{|c|c|c|}
\hline Various type source of campaign & Sample (n) & $\begin{array}{l}\text { Percentage } \\
\text { (\%) }\end{array}$ \\
\hline 1. Supermarket/hypermarket & 171 & 65.3 \\
\hline 2. Media (radio, television, newspaper) & 53 & 20.2 \\
\hline 3. Friend/neighbors & 19 & 7.3 \\
\hline $\begin{array}{l}\text { 4. Looking consumers bring shopping } \\
\text { bags }\end{array}$ & 10 & 3.8 \\
\hline 5. Other family member & 5 & 1.9 \\
\hline 6. No comment & 4 & 1.5 \\
\hline Total sample & 262 & 100.0 \\
\hline
\end{tabular}

Kajian komprehensif di pasaraya mungkin diperlukan untuk memahami amalan pengguna semasa kempen bebas beg plastik ini berlangsung. Dapatan kajian mendapati tingkah laku pengguna pada beg plastik adalah sebanyak 45 peratus penggunaan sekunder plastik sebagai beg sampah (Jadual 4).

Jadual 4: Penggunaan semula beg plastik

\begin{tabular}{lcc}
\hline Various secondary use of plastic bag & Sample (n) & $\begin{array}{l}\text { Percentage } \\
(\%)\end{array}$ \\
\hline 1. Reused for garbage bag & 225 & 45.0 \\
2. Reused for carrying goods & 159 & 32.0 \\
3. Thrown in with other waste & 68 & 14.0 \\
4. Reused for shopping & 46 & 9.0 \\
Total sample & 498 & 100.0 \\
\hline
\end{tabular}


Pengguna yang menyokong ke arah pemerkasaan kempen bebas beg plastik dapat mengurangkan penggunaan beg plastik. Walaupun plastik memberi kesan kepada alam sekitar, kira-kira 32\% pembawa beg plastik pasaraya digunakan untuk membawa barangan lain seperti 9\% untuk membeli-belah. Hanya 14\% daripada pembawa beg plastik yang benar-benar boleh dilupuskan dengan jenis sisa lain (Jadual 4). Walaupun, penggunaan beg plastik memberi kesan negatif terhadap alam sekitar, dari perspektif tingkah laku pengguna, penggunaan semula beg plastik untuk pelbagai tujuan menunjukkan amalan tingkah laku pengguna yang positif dengan $41 \%$ daripada penggunaan sekunder beg plastik telah menunjukkan potensi tingkah laku pembawaan beg membelibelah yang boleh digunakan semula untuk dilaksanakan. Ia adalah pendekatan yang positif jika ditambah dengan kempen pendidikan Membawa Beg Beli Belah Sendiri.

Hasil daripada sesi temu bual dengan pengusaha pasaraya yang terlibat dalam Kempen Bebas Beg Plastik menyimpulkan terdapat beberapa amalan tidak beretika yang telah dilakukan oleh seperti menghilangkan bakul di pasaraya dan penyalahgunaan troli pasaraya untuk mengangkut barangan ke rumah terutamanya bagi pasaraya yang terletak bersebelahan dengan kawasan kediaman mereka.

Tingkah laku negatif pengguna ini boleh dikenal pasti sebagai tindakan protes terhadap kemudahan membeli-belah sebelumnya dan dikelaskan sebagai tingkah laku anti-penggunaan (Penaloza dan Harga 1993). Senario ini menunjukkan kelakuan pengguna terhadap amalan tingkah laku dan membawa kepada kelemahan melalui pelaksanaan kempen bebas plastik. Tingkah laku pengguna dapat difahami dengan baik sejak diagihkan beg plastik percuma di pasaraya telah dirasai sebagai norma dan dianggap sebagai hak pengguna. Dari perspektif pelaksanaan kempen bebas beg plastik akan memberi impak kepada pihak pentadbiran serta pihak berkuasa perlu memainkan peranan yang lebih besar dalam memastikan keberkesanan kempen ini dan dpatuhi oleh semua pasaraya (Convery et al., 2007).

\section{Kesimpulan}

Pelbagai organisasi yang meliputi sektor yang berbeza sememangnya berperanan penting dalam memperkasakan kempen bebas beg plastik bagi melestarikan alam sekitar serta mencorakkan persekitaran yang baharu agar lebih kondusif di sekeliling mereka. Pencemaran alam sekitar yang berpunca daripada produk berasaskan plastik bukanlah isu baharu untuk diperdebatkan, namun sikap dan tabiat masyarakat adalah isu yang harus diberi perhatian serius. Misalnya, mentaliti masyarakat walaupun kerap kali digerakkan dengan pelbagai kempen penjagaan alam sekitar terutama kempen bebas beg plastik namun ketidakbiasaan mengubah sikap peka terhadap alam sekitar telah membebankan pihak berkepentingan untuk menggerak dasar pembangunan negara yang mampan. Justeru, struktur rangkaian tadbir urus yang telah dianalisis melalui tiga peringkat iaitu tahap global yang memberi tumpuan kepada populasi rangkaian corak hubungan keseluruhannya, tahap tempatan yang memfokuskan kepada pembahagian rangkaian ke dalam sub-kumpulan serta tahap individu yang menekankan struktur ciri kepentingan dan kedudukan dalam rangkaian.

Namun, kelemahan struktur rangkaian adalah agak rendah memandangkan proses tadbir urus kempen bebas beg plastik ini masih di tahap yang sama, dengan keupayaan untuk menyelaraskan tindakan bersama adalah terhad. Pendekatan urus tadbir wajar diketengahkan atau dimantapkan pada masa kini kerana dek kerana masih wujud ketidakberkesanan 
dalam sistem pengurusan alam sekitar khususnya penglibatan pengurusan sampah sarap bahan plastik yang tidak terurai. Malah, tahap tempatan atau "meso" menjadi tumpuan utama dengan penglibatan kerjasama kerajaan negeri dan persekutuan bagi mendalami perlaksanaan dasar yang tidak dapat dilaksanakan pihak berkuasa tempatan kerana kemampuan serta limitasi yang terhad. Justeru, kerajaan persekutuan perlu mengkaji semula perihal pindaan akta berkenaan larangan penggunaan beg plastik bagi memastikan matlamat kempen ini dapat dicapai dalam masa terdekat.

\section{Rujukan}

Akulian, A., Karp, C., Austin, K., \& Durbin, D. (2007). Plastic bag externalities and policy in Rhode Island. Environmental \& Resource Economics, 38, 1-11.

Ayalon, O., Goldrath, T., Rosenthal, G., \& Grossman, M. (2009). Reduction of plastic carrier bag use: A analysis of alternatives in Israel. Waste Management, 29, 3.

Baker, A. R. (2010). "Fees on plastic bags: Altering consumer behavior by taxing environmentally damaging choices" Expresso.http://works.bepress.com/ alice_baker/1.

Brace, I. (2004). Questionnaire design: How to plan, structure and write survey material for effective market research. London: Market Research in Practice Series.

Cherrier, H. (2006). Consumer identity and moral obligations in non-plastic bag consumption: A dialectical perspective. International Journal of Consumer Studies, 30, 515-523

Convery, F., McDonnell, S., \& Ferreira, S. (2007). The most popular tax in Europe? Lessons from the Irish plastic bags levy. Environmental Resources Economics, 18(4), 367-371.
DANIDA. (2010). Solid Waste Management Component Study on Rural Household Waste Management in Peninsular Malaysia. Consultancy Report of Danish International

Development Agency (DANIDA) for Ministry Housing and Local Government (Ref.104. Malaysia.1.MFS.86).

Department of Statistic. (2006). Section methodology and research. Malaysia: Department of Statistics, Malaysia.

Dikgang, J., \& Visser, M. (2010). Behavioral response to plastic bag legislation in Botswana.

Discussion Papers dp-10-13-efd. Resources For the Future. Published: Percetakan Nasional Malaysia Berhad; August 30, (2010).

Engel, J. F., Blackwell, R. D., \& Miniard, P. W. (1990). Consumer behavior. Chicago: Dryden Press.

Harrell, M. C., \& Bradley, M. A. (2009). Data collection methods: Semistructured interviews and focus. US: Rand Corp, p. 144.

Hasson, R., Leiman, A., \& Visser, M. (2007). The economics of plastic bag legislation in South Africa. South African Journal of Economics, 75, 66-83.

Hines, J. M., Hungerford, H., \& Tomera, A. (1987). Analysis and synthesis of research on Responsible environmental behavior. Journal of Environmental Education, 18, 1-8.

Hoggard, S. (2010). Plastic politics in Malaysia. Plastic in packaging (March Edn.). UK:

Sayers Publishing Group Ltd. http:// www.sayersonline.com/catalog/index. php. 
Iyer, R., \& Muncy, J. A. (2009). Purpose and object of anti-consumption. Journal of Business Research, 62, 160-168.

Krajhanzl, J. (2010). Environmental and pro-environmental behaviour. School and Health, 21, 251-274.

Kraus, S. (1995). Prediction of behavior: A meta-analysis of the empirical literature. Personal Psychology Bulletin, 21(1), 58-75.

Lee, M. S. W., Motion, J., \& Conroy, D. (2009). Anti-consumption and brand avoidance.

Journal of Business Research, 62, 169180.

Ministry of Domestic Trade, Cooperatives and Consumerism (MDTCC). (2012). Official site http://www.kpdnkk. gov.my/web/guest/media-majlispelancaran-kempen-kurangkan penggunaan-beg-plastikdan-haritanpa-beg-plastik. Last Access January 12, 2012.

Park, J. (2009). The search for an other way to shop. Packaging News(FEB.), pp. 28-29.

Penaloza, L., \& Price, L. L. (1993). Consumer resistance: A conceptual overview. Advance Consumer Research, 20, 123-128.

Pigou, A. C. (1920). The economics of welfare. London: Macmillan.

Romer, J. R. (2010). The evolution of San Fransisco's plastic bag ban. Golden Gate U. Envtl. L.J. pp. 439, 440.

Sharp, A., Hoj, S., \& Wheeler, M. (2010). Proscription and its impact on anticonsumption behaviour and attitude: The case of plastic bags. Journal of Consumer Behaviour,9,4.

Solid Waste Collection, Removal and Disposal By Laws 2007, Shah Alam
City Council. http://www.mbsa.gov. my/undang_undang_kecil. Last Access March 19, 2012.

Solid Waste and Public Cleansing Management Corporation Act (SWPCMCA) 2007.

Published: Percetakan Nasional Malaysia Berhad; August 30, (2007).

Tan, W. C. M., \& Mehta, S. C. (1994). Merchandise vs. facility-driven services: Relative role in consumer choice of supermarkets in Singapore. Asia Pacific Advances in Consumer Research, 1, 160-164.

The Malaysian Insider. March 7, (2012). Plastic makers gaining from Pakatan's non-bag days.

The Star. January 4, 2010. Shoppers caught unawares by 'no plastic bag day' c a mpaign.thestar.com.my/ news/story.asp?file $\quad=/ 2010 / 1 / 4 /$ nation/5406764\&sec nation. Last Access March 12, 2012.

The Star. January 11, (2010). Most shoppers happy with plastic bag ruling. http://thestar.com.my/metro/story. asp?file $=/ 2010 / 1 / 11 /$ central $/ 5446161$

Wall, A. P. (2005). Government demarcating: Different approaches and mixed messages.

European Journal of Marketing, 39(5/6), 421-427.

Wright, M., \& Klyn, B. (1998). Environmental attitude-behaviour correlations in 21 countries. Journal of Empirical Generalisations in Marketing Science, 3, 42-60.

Zavestoski, S. (2002). The socialpsychological bases of anticonsumption attitudes.

Psychology \& Marketing, 19(2), 149165. 